\title{
Primeros estadíos del ciclo de vida de peces nativos del Río San Pedro (Cuenca del Río Valdivia, Chile)
}

\section{First stages of the life cycle in native fish from the San Pedro River (Valdivia River Basin, Chile)}

\author{
Germán Montoya ${ }^{1 *}$, Alfonso Jara ${ }^{1}$, Katherin Solis-Lufi ${ }^{1}$, Nicole Colin ${ }^{1,2}$ \& Evelyn Habit ${ }^{1}$ \\ ${ }^{1}$ Unidad de Sistemas Acuáticos, Centro EULA, Universidad de Concepción. Casilla 160-C. \\ ${ }^{2}$ Departamento de Zoología, Facultad de Ciencias Naturales y Oceanográfica, Universidad de Concepción. \\ *Email: gemontoya@udec.cl
}

\begin{abstract}
RESUMEN
Los estadíos de huevos, larvas y juveniles de los peces de agua dulce nativos de Chile son prácticamente desconocidos. Conocer su estacionalidad, morfología y uso de hábitat es relevante para comprender su biología y permitir la conservación de esta ictiofauna altamente amenazada. Asimismo, los primeros estadíos del ciclo de vida de los peces determinan la persistencia de las poblaciones en el tiempo. Dado esto, el objetivo del presente trabajo fue dar a conocer y describir los resultados de intensivos muestreos (465 días) destinados a encontrar los primeros estadíos de las 14 especies nativas que habitan el río San Pedro (cuenca del Valdivia). Los muestreos se efectuaron desde octubre de 2005 a marzo de 2008. Se encontraron huevos, larvas y juveniles de Galaxias maculatus, Basilichthys australis y Percilia gillissi; larvas y juveniles de Geotria australis y Trichomycterus areolatus, y juveniles de Diplomystes camposensis, Percichthys trucha y Cheirodon australe. En cada caso se describe la época y hábitat de ocurrencia, así como sus características morfológicas generales, lo cual para $P$. gillissi constituye la primera descripción de sus estadíos de desarrollo embrional y larvario. En general, se aprecia una segregación espaciotemporal de las épocas de desove y crianza de larvas marcada por el uso de las planicies de inundación como sitios de crianza. La extensión temporal de este estudio a escala de ambientes ribereños sugeriría que los esfuerzos de búsqueda de aquellos primeros estadíos no detectados podrían enfocarse en ambientes más profundos o correntosos.
\end{abstract}

Palabras clave: Huevos, larvas, juveniles, peces nativos, Chile.

\begin{abstract}
Eggs, larvae and juveniles stages of the Chilean native freshwater fish are practically unknown. To know their seasonality, morphology and habitat use is relevant to understand their biology and to allow the conservation of this highly threatened ichthyofauna. Likewise, the early stages of fish's life cycle are highly labile and their success determines the persistence of the populations over time. For this reason the aims of this work is to report and describe the results of intensive samplings performed to find the early stages of the 14 native species that inhabit in the San Pedro River (Valdivia river Basin). Samplings were done during 465 days along the river, from October 2005 to March 2008. We found eggs, larvae and juveniles of Galaxias maculatus, Basilichthys australis and Percilia gillissi, larvae and juveniles of Geotria australis and Trichomycterus areolatus; and juveniles only of Diplomystes camposensis, Percichthys trucha and Cheirodon australe. We describe the season and habitat of occurrence, as well as their general morphological characteristics. This is the first description of embryonic and larval development stages for $P$. gillissi. A spatial-temporal segregation of the spawning and larvae rearing is observed, mainly marked by the use of the floodplain as rearing sites. The temporal extention of this study at riparian scale suggests than efforts in search of early stages of knowless species would be focus in deeper and/or rushing environments.
\end{abstract}

KeYwords: Eggs, larvae, juveniles, native fish, Chile. 


\section{INTRODUCCION}

Los peces dulceacuícolas nativos de Chile son los vertebrados menos estudiados a nivel nacional (Vila \& Pardo 2008), principalmente en relación a su reproducción y ciclos de vida (Habit et al. 2006). Así, la mayoría de los primeros estadíos de desarrollo de las especies nativas son desconocidos. Ello se debe en parte a la falta de campañas de búsqueda con ese objetivo, ya que al requerir de técnicas específicas de recolección en determinados hábitat y épocas del año (Nakatani et al. 2001), implican tiempo y dedicación exclusiva (Nellen \& Schnack 1975; Bagenal \& Nellen 1980; García de Jalón et al. 1993). No obstante, los primeros estadíos de vida de los peces son relevantes para el conocimiento de la biología y sistemática de los mismos (Ahlstrom \& Moser 1976), además que constituyen las fases críticas para el éxito del reclutamiento anual y la persistencia de las poblaciones (García de Jalón et al. 1993). Asimismo, huevos y larvas de peces presentan requerimientos ecológicos propios (e.g. nutricionales y energéticos), frecuentemente distintos a los de adultos (Nakatani et al. 2001). Por tanto, el estudio de estos estadíos se torna imprescindible para el entendimiento de la historia de vida y de la dinámica de las poblaciones naturales de peces (Lasker 1987; Nakatani et al. 2001). Del mismo modo, constituyen una herramienta clave en estudios ambientales que consideran aspectos como la determinación y evolución de stock, identificación y delimitación de áreas de desove, e importancia relativa de los cuerpos de agua para el reclutamiento (Hempel 1973). Esto último es de fundamental importancia en la implementación de medidas de manejo y mantención de áreas prioritarias para la conservación de poblaciones amenazadas, facilitando de esta manera la evaluación de los impactos específicos y la determinación de la planificación de programas tendientes a revertir o mitigar tales efectos (Nakatani et al. 2001; Habit et al. 2006). Dado esto, el objetivo del presente trabajo es dar a conocer y describir los resultados de intensivos muestreos destinados a encontrar los primeros estadíos de las 14 especies nativas que habitan el río San Pedro (cuenca del río Valdivia). Consecuentemente, esta contribución brinda información descriptiva e inédita para algunas especies y complementaria para otras, sobre aspectos cualitativos del ciclo de vida y zonas de postura, con especial énfasis en huevos y larvas. Así también, se presentan observaciones sobre aspectos reproductivos de las especies estudiadas, logradas mediante intensivas campañas de terreno efectuadas durante más de dos ciclos anuales consecutivos.

\section{MATERIALES Y MÉTODOS}

ÁREA DE ESTUDIO Y MUESTREO

Los muestreos de huevos, larvas y juveniles de peces nativos se llevaron a cabo en el río San Pedro, tributario de la cuenca del río Valdivia (3946' - 3951' S). En este sistema fluvial de $40 \mathrm{~km}$ de longitud, se establecieron 35 sitios de muestreo, ubicados desde su origen, en el desagüe del lago Riñihue hasta la confluencia con el río Quinchilca, abarcando todo su recorrido. El estudio se realizó entre octubre de 2005 y marzo de 2008, efectuando un total de 465 días efectivos de muestreo.

Se utilizaron técnicas específicas para la búsqueda y captura de los distintos estados de desarrollo, teniendo en cuenta los requerimientos ecológicos de cada especie (e.g. uso de hábitat, comportamiento y/o capacidad de movimiento), además de la prospección visual minuciosa de cada sector y de los distintos hábitats. La colecta de larvas fue llevada a cabo con redes de ictioplancton, redes Surber y red de tipo Dip-net, las cuales fueron arrastradas desde una embarcación o desde las orillas, tanto a superficie como a profundidad. La búsqueda de huevos demandó la revisión exhaustiva de distintas zonas y hábitats del río, incluyendo vegetación acuática y terrestre, intersticios entre el sustrato o en la cara inferior de bolones. Debido al pequeño tamaño y fragilidad de los huevos, se capturaron principalmente de forma manual encontrándolos por inspección visual. Las mediciones de los diferentes estadíos de desarrollo se realizaron con un vernier caliper $0,01 \mathrm{~mm}$.

Metodología de LABORATORIO

Las muestras de huevos y de larvas se transportaron al laboratorio para luego ser incubadas. Los huevos se dispusieron en placas petri tapadas con malla de diámetro menor a $1 \mathrm{~mm}$ y puestas dentro de bandejas de incubación. Para reducir la contaminación producida por hongos éstos se mantuvieron con circulación constante de agua. A cada muestra se le siguió su desarrollo ontogenético, hasta lograr identificar las especies a la que correspondían. Esto también fue corroborado mediante el hallazgo de hembras con ovocitos maduros (ver estados gonádicos en Peredo \& Sobarzo 1993, 1994) en sitios de posturas y por análisis genético de secuenciación mitocondrial. Los métodos y análisis genéticos efectuados se entregan en Victoriano et al. (2012). Las mediciones de huevos y etapas pre-eclosión se llevaron a cabo mediante el software de análisis de imagen Image ReoPlus 4.5 for windows.

La terminología usada para describir los diferentes estadíos de desarrollo en peces es variada y dispersa debido a la complejidad de estrategias reproductivas y de desarrollo. Por ende, para describir tales fases se siguió la nomenclatura de Nakatani et al. (2001), la cual condensa las principales etapas iniciales de desarrollo embrionario y postembrionario de peces de agua dulce. Estas se basan principalmente en la secuencia de desarrollo de la aleta caudal y sus elementos de soporte. Finalmente, las descripciones se complementan con 
antecedentes previos obtenidos de análisis bibliográfico.

\section{RESULTADOS Y DISCUSION}

Durante el estudio se encontró un total de 14 especies nativas [Geotria australis Gray 1851, Cheirodon australe Eigenmann 1927, Trichomycterus aerolatus (Valenciennes 1840), Hatcheria macraei (Girard 1855), Diplomystes camposensis Arratia 1987, Galaxias maculatus (Jenyns 1842), Galaxias platei Steindachner 1898, Brachygalaxias bullocki (Regan 1908), Aplochiton taeniatus Jenyns 1842, Aplochiton zebra Jenyns 1842, Basilichthys australis Eigenmann 1927, Odontesthes mauleanum (Steindachner 1896), Percichthys trucha (Valenciennes 1833) y Percilia gillissi Girard 1854]. De éstos, se encontraron huevos, larvas y juveniles de G. maculatus, B. australis y P. gillissi; larvas y juveniles de G. australis y $T$. areolatus; y solamente juveniles de $D$. camposensis, $P$. trucha y Ch. australe. La Figura 1 resume los períodos en que se efectuaron los hallazgos de huevos y larvas de las distintas especies en el área de estudio, los cuales se describen a continuación en orden de los hallazgos registrados.

Galaxias maculatus. Se encontraron huevos de G. maculatus ("puye") en pozas someras del río formadas principalmente en las planicies de inundación, con una profundidad promedio de $30 \mathrm{~cm}$, sustrato fino, enfangado y con abundante vegetación sumergida y emergida. En algunos casos se les encontraron adheridos a raíces de vegetación terrestre sumergida. La temperatura de las pozas fue en promedio un grado mayor que en el cauce del río y osciló entre $16,4^{\circ} \mathrm{C}$ a $19,7^{\circ} \mathrm{C}$. Los hallazgos de huevos ocurrieron en dos períodos del ciclo anual, el primero entre noviembre a enero y luego entre julio a septiembre (Fig. 1). En el mismo tiempo de hallazgos de huevos, específicamente en julio, se encontraron hembras con ovocitos en madurez final evidenciado por un abultamiento abdominal semitranslúcido (Fig. 2). Esto se ajusta a lo descrito para ciclos gonádicos registrados en poblaciones diádromas de esta especie en el río Cautín (IX Región, Chile) (Peredo \& Sobarzo 1994). Asimismo, el primer período concuerda con los reportes previos de Barriga et al. (2002) para poblaciones residentes ("landlocked") de Argentina. En tanto, el segundo período concuerda con el registro de Campos (1970) para poblaciones diádromas en esta misma cuenca hidrográfica. Sin embargo, estos períodos varían con lo reportado por Barriga et al. (2007) para poblaciones landlocked en un río norteño de Patagonia (septiembre-noviembre) y con lo reportado por Boy et al. 2009 para poblaciones diádromas del río Ovando en Tierra del Fuego Argentina (octubre y febrero). También varía con los registros de Pollard (1971) y Chapman et al. (2006), para poblaciones landlocked en Nueva Zelanda (julio-octubre) y Australia (marzo-abril), respectivamente.
Los huevos son transparentes, sin filamentos (Fig. 3), y comparativamente más pequeños que los de $B$. australis. Cada huevo está recubierto de mucílago, lo cual les permite adherirse a la vegetación. En los primeros estadíos de desarrollo embrionario poseen gran cantidad de gotas oleosas en su interior, lo cual concuerda con lo reportado anteriormente por Benzie (1968a). Posteriormente, se reduce a una única gota oleosa. Cussac et al. (2004) comentan que los huevos de poblaciones landlocked son ligeramente de menor tamaño (1,0-1,1 mm; Benzie 1968a) que los de poblaciones diádromas (1,2 mm; Battini 1998).

Los huevos llevados al laboratorio eclosionaron entre 2 a 3 días después, obteniéndose el estado larval vitelino. Esta fase, la cual está definida por la presencia de saco vitelino, se extendió por 7 días. Este período se establece por el consumo de las reservas vitelinas, el cual en G. maculatus es bastante rápido y depende de la temperatura (Benzie 1968b). Antes de la eclosión, el embrión final se enrolla aproximadamente dos veces en sí mismo (Fig. 3), lo cual también ayuda a ejercer presión para la ruptura del corión y la posterior liberación. La talla de larvas eclosionadas fue de 6-7 mm, siendo morfológicamente alargadas y transparentes. La eclosión en el río ocurrió en sitios empozados con escasa a nula corriente. Durante enero se registró un aumento significativo de estadíos larvales, lo cual se manifiesta mucho más claramente en la zona litoral del lago Riñihue. La eclosión de huevos de poblaciones diádromas ha sido descrita como sujeta a las fluctuaciones de las mareas (Benzie 1968b), y por ende pueden existir diferencias en los tiempos de desove entre poblaciones diádromas y landlocked. De igual forma pueden diferir entre poblaciones residentes a distintas latitudes (Barriga et al. 2007; Boy et al. 2009). Las larvas se alimentan principalmente de cladóceros (Bosmina longirostris) y copépodos (Harpacticoida y Cyclopoida) (Cervellini et al. 1993).

El estado juvenil denominado comúnmente como cristalino (o "whitebait"), se caracteriza por su transparencia con tonos verde-azulados. Este estadío fue abundante en el lago Riñihue durante todo el año (Fig. 1) y en el río estuvo asociado a pozas someras donde se encontró en menor abundancia. En poblaciones diádromas, este estado es alcanzado en el mar, extendiéndose por ca. 6 meses en él, para luego migrar a ríos y alcanzar la madurez (sensu McDowal 1976). También pueden mantener hábitos marinos durante la adultez temprana para luego remontar aguas continentales y reproducirse (Pollard 1971). Sobre la base de información de tiempos y sitios de ocurrencia, postulamos tres posibles orígenes de los cristalinos en el río San Pedro: i) dado que la abundancia de cristalinos disminuye desde el lago Riñihue hacia aguas abajo a lo largo del río, podrían corresponder a una población landlocked asociada al lago; ii) podrían constituir una cohorte proveniente de ambientes estuarinos 
o potamales (rio Calle-Calle) que alcanzarían su estado de madurez sexual dentro del río San Pedro dada la naturaleza diádroma de la especie (McDowal 1976; Barriga et al. 2007); iii) dado que esta fase se presenta durante todo el año es posible que los cristalinos del río presenten una población landlocked del sistema fluvial y no del lago. Respecto a esta última opción, los hallazgos de huevos soportan esta posibilidad. Estos tres escenarios son probablemente no excluyentes, considerando principalmente que los estudios genéticos (Victoriano et al. 2012) muestran una alta estructuración genética entre las poblaciones del lago Riñihue, el río San Pedro y el río Calle-Calle.

Basilichthys australis. Se encontraron posturas de huevos de B. australis ("pejerrey chileno") en planicies de inundación con moderada velocidad de corriente (entre 0,3 y $0,5 \mathrm{~m} / \mathrm{s}$ ) y abundante vegetación terrestre (zarzamora, pasto, arbustos). Las posturas se encuentran en forma de racimo con un filamento central, el cual se enrolla a la vegetación (Fig. 4), lo que permite que la postura quede expuesta a la corriente con alta oxigenación. Los huevos se encontraron solamente entre los meses de noviembre y diciembre (Fig. 1), es decir, en un rango temporal menor al descrito para poblaciones del río Maipo por Moreno et al. (1977; agosto a noviembre) y Huaquín \& Araya (1986; agosto a diciembre). La época de postura de huevos de B. australis en el río San Pedro ocurrió consistentemente en los tres años de estudio sólo entre noviembre y diciembre, lo que sugiere que la menor temperatura de los ríos del sur puede ser una limitante para iniciar el período reproductivo con anterioridad (e.g. agosto, como en el río Maipo). En todas las oportunidades, el hallazgo de huevos ocurrió directamente después de crecidas del río producto de lluvias de primavera, durante las cuales aumenta el nivel del agua $(\sim 1,5 \mathrm{~m})$ y el río ocupa las planicies de inundación. Esto sugiere fuertemente, que el incremento de caudal gatilla el comportamiento de desove en esta especie.

Los huevos fecundados son transparentes, poseen numerosas gotas oleosas de color amarillento, y alcanzaron 1,8 $\mathrm{mm}$ de longitud (Fig. 5). Estos presentan 2-3 filamentos cortos. Comparativamente, son de mayor tamaño que los huevos de $P$. gillissi $(1 \mathrm{~mm})$ y levemente menores a los registrados por Huaquín \& Araya (1986) para B. australis (2,2-2,3 mm). De acuerdo a Huaquín \& Araya (1986) los huevos recién desovados son blandos y opacos, en tanto que luego de la fecundación sufren cambios en la membrana externa, la cual se hidrata y se endurece. La presencia de filamentos en huevos es característico de aterínidos (Huaquín \& Araya 1986).

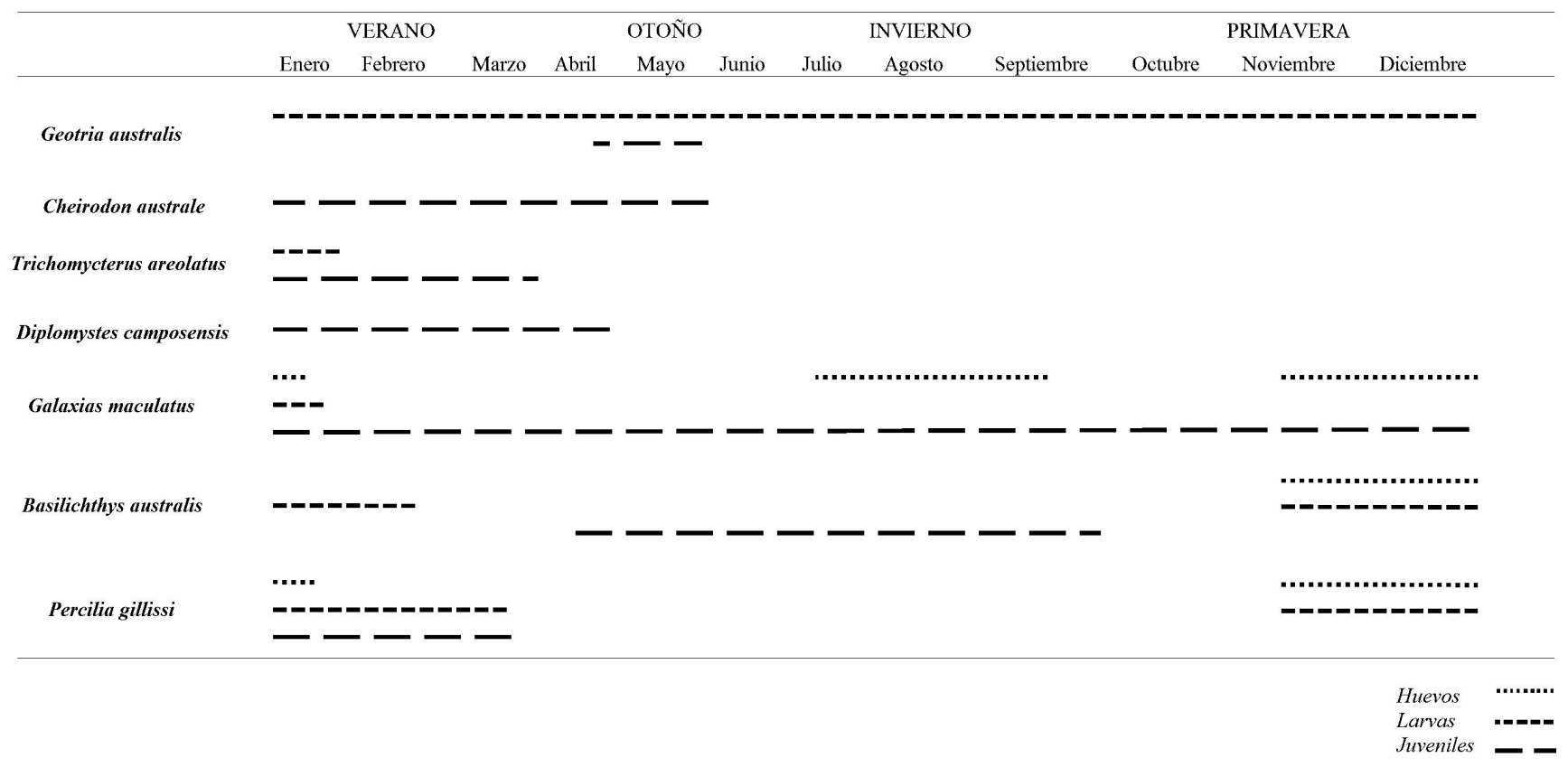

Figura 1. Esquema del período anual de desove y reclutamiento basado en los hallazgos de huevos, larvas y juveniles.

Figure 1. Annual timetable of spawning and recruitment based on eggs, larvae and juveniles findings. 


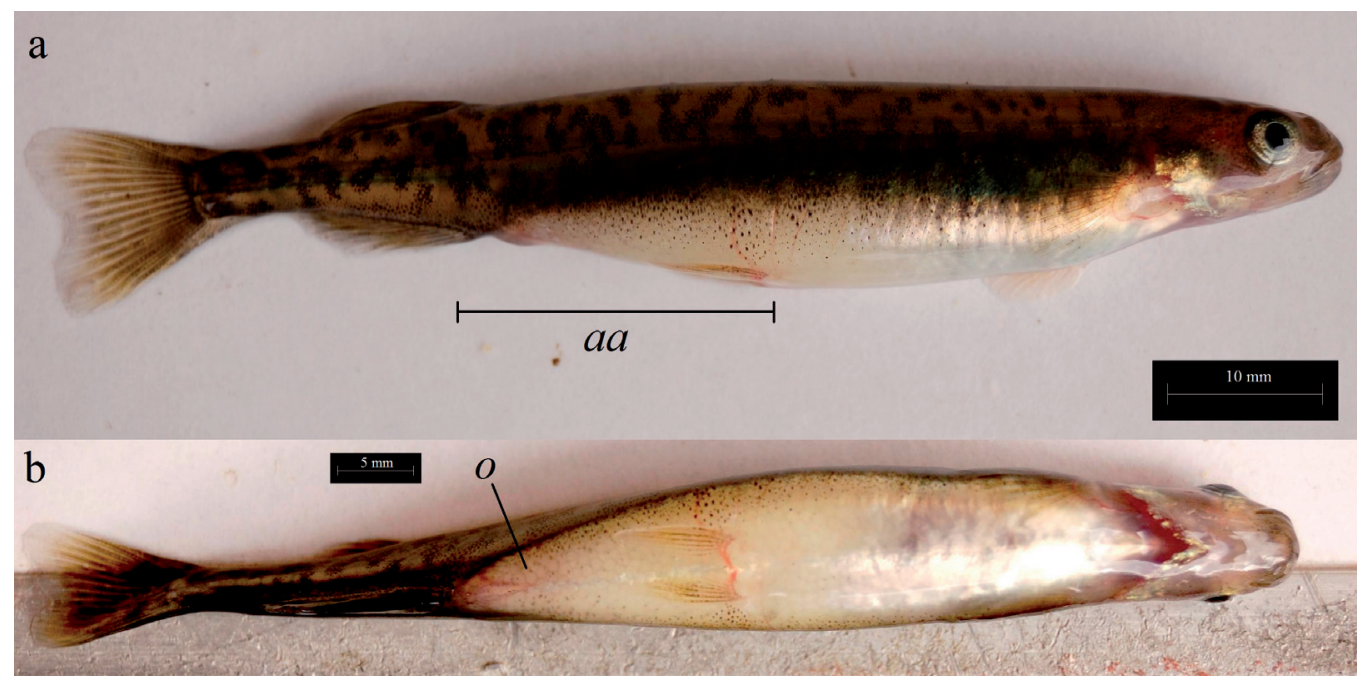

Figura 2. Hembra de Galaxias maculatus colectada en julio de 2008 en el río San Pedro. a) Vista lateral, donde se observa el abultamiento abdominal $(a a)$, y b); vista ventral posterior con ovocitos $(o)$ maduros.

Figure 2. Female of Galaxias maculatus collected in july 2008 in San Pedro river. a) Lateral view, with abdominal bulge ( $a a$ ), and b) ventral posterior view with mature ovocytes $(o)$.

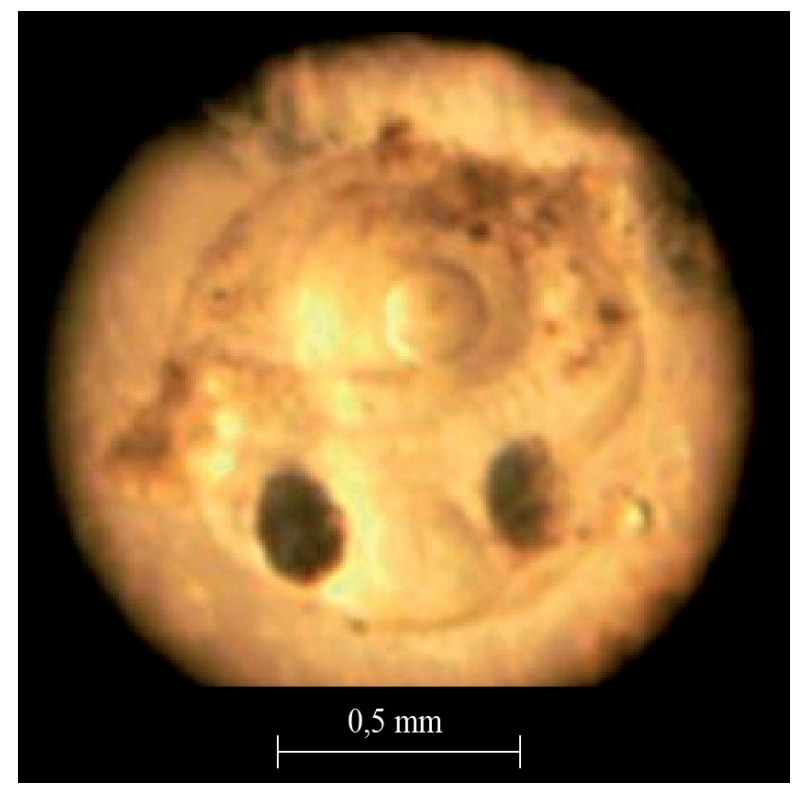

FIgURA 3. Embrión final de Galaxias maculatus en un estado avanzado de desarrollo.

FIGURE 3. Galaxias maculatus terminal embryo in advanced stage of development. 


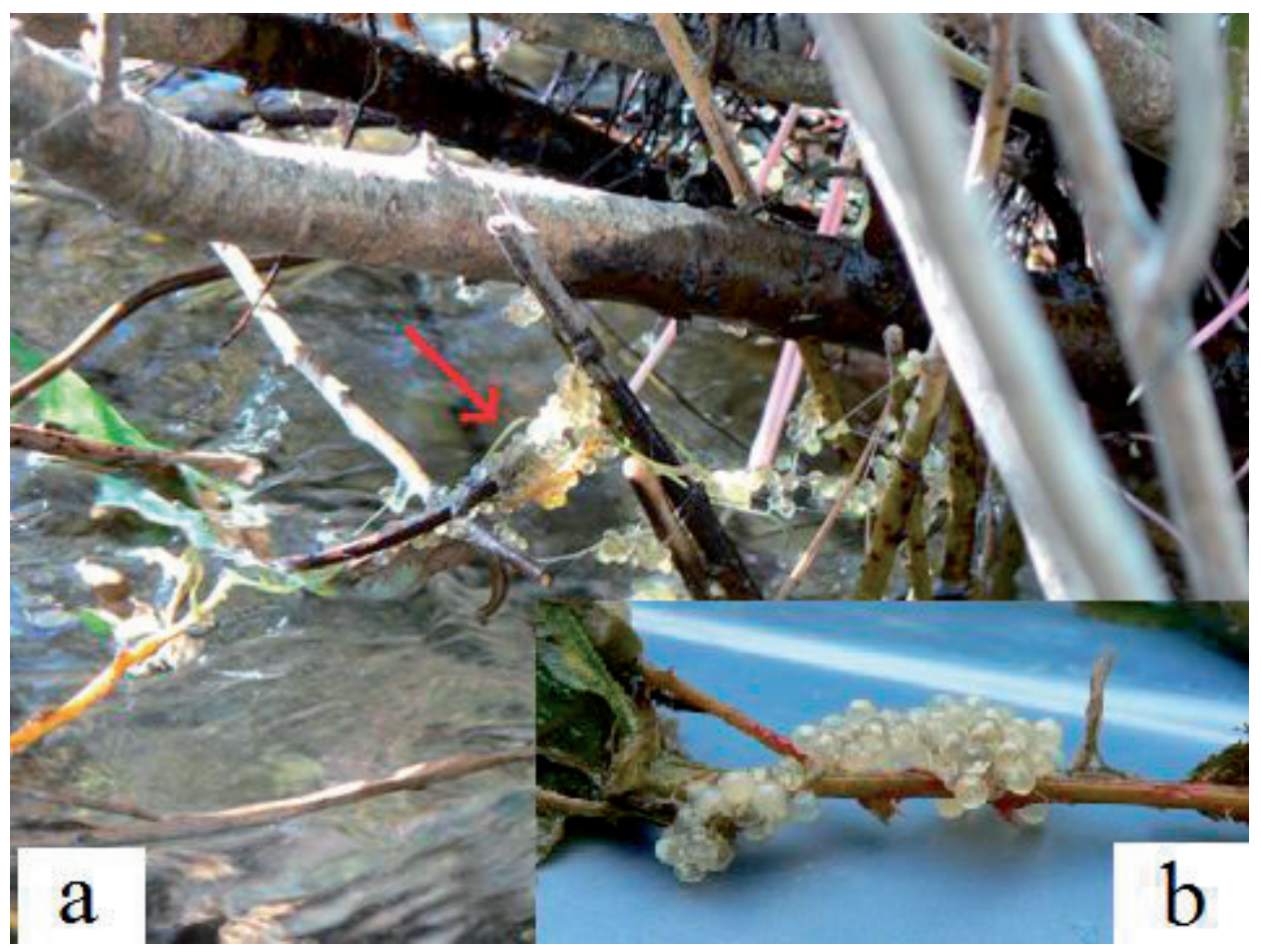

Figura 4. a) Estrategia de sujeción de la postura de huevos a la vegetación ribereña (flecha); y b) detalle del racimo de huevos de Basilichthys australis.

Figure 4. a) Attachment strategy of Basilichthys australis eggs to the riverine vegetation (arrow); and (b) egg cluster detail.

$\mathrm{Al}$ incubar los huevos en el laboratorio entre $14^{\circ}$ y $22^{\circ} \mathrm{C}$, se reconocieron los siguientes estados de madurez embrional. Embrión inicial. El blastodermo ya posee una forma alargada y consistente, expandiéndose sobre el vitelo cubriendo casi la mitad de su perímetro. El embrión no posee pigmentación, sin miómeros aparentes, con gotas oleosas frente a la placa neural, abundante vitelo, y tamaño del embrión pequeño en relación al vitelo (Fig. 5). A pesar de los cambios morfogenéticos evidenciados por la aparición de las vesículas ópticas, el embrión aún no libera la región caudal, la cual se mantiene adosada al vitelo. Esta fase corresponde al período de movimientos morfogenéticos, caracterizado por la dinámica epibólica del embrión en desarrollo (sensu Huaquín \& Araya 1986), específicamente al estado 7. Hasta este estado han transcurrido 24 horas desde la fecundación (sensu Huaquín \& Araya 1986). Embrión final: Embrión desarrollado, de mayor tamaño, pero aún menor al tamaño del vitelo. Mayor desarrollo cefálico, ojos pigmentados de gran tamaño, pigmentación cefálica dorsal muy notoria, y se aprecia un corazón primordial funcional. La porción caudal ya se ha desprendido del vitelo y se flexiona sobre él, pero aún no alcanza su largo máximo. Embriones con movimiento aproximadamente al décimo día. Las múltiples gotas oleosas de las fases tempranas se unen para formar una única gota (Fig. 6). Esta fase corresponde al período de organogénesis descrito por Huaquín \& Araya (1986), probablemente al Estado 16-17 descrito por tales autores, cuando han transcurrido 240-288 horas. Al eclosionar tienen un largo de 8 mm (sensu Huaquín \& Araya 1986).

En el río, las larvas de $B$. australis fueron encontradas pocos días después del hallazgo de huevos. Estas fueron encontradas desde noviembre hasta febrero. Las larvas se encuentran en grupos numerosos y compactos, raramente de manera dispersa. El hábitat de las larvas corresponde principalmente a riberas inundadas y ambientes de pozas someras. El substrato no es específico, encontrándose tanto en hábitat con fango, rocas o pasto, pero siempre con muy baja a nula velocidad de corriente $(\sim 0 \mathrm{~m} / \mathrm{s})$. Estas pozas poseen también una alta productividad de microorganismos tales como Daphnia sp., que son utilizados como alimento de larvas, lo que se evidenció por la inspección microscópica del contenido intestinal. En el río, la eclosión de los huevos ocurre secuencialmente desde aguas abajo hacia aguas arriba, estando asociado a las mayores temperaturas del agua en la parte baja del río. Durante la época de reproducción, los adultos forman grandes cardúmenes en áreas donde la corriente es lenta y la profundidad de las aguas es mayor (Vila et al. 1981). Así, en el río San Pedro es común ver estas agrupaciones hacia la zona alta del río en pozones 
profundos o zonas de mediana velocidad durante la época reproductiva.

Percilia gilissi. Se encontraron huevos de "carmelitas" a lo largo de todo del río, asociados a ambientes de poza con leve corriente $(<0,2 \mathrm{~m} / \mathrm{s})$. Pueden encontrarse adosados a la superficie inferior de rocas o en pequeñas oquedades del sustrato rocoso a una profundidad de $10-50 \mathrm{~cm}$. Están presentes en ambientes con o sin vegetación asociada, e incluso bajo raíces de arbustos (e.g. Baccharis spp). Entre noviembre y diciembre se comienzan a encontrar huevos pero en bajas abundancias, aumentando notablemente en enero. Las únicas observaciones previas correspondían a las realizadas por Killian \& Campos (1969) en el litoral del lago Panguipulli, donde describen desoves en cámaras vibrátiles de esponjas (Spongilla igloviformis) durante la primavera. Duarte et al. (1971) suponen que en el río Maipo esta especie presenta la misma estrategia reproductiva, a pesar de no presentar observaciones más detalladas acerca de ello. Es decir, esta especie recurre a un amplio tipo de estrategias de desove, lo cual concuerda con su generalismo en el uso de hábitats (García et al. 2012) y su alta abundancia en el río San Pedro (Colin et al. 2012).

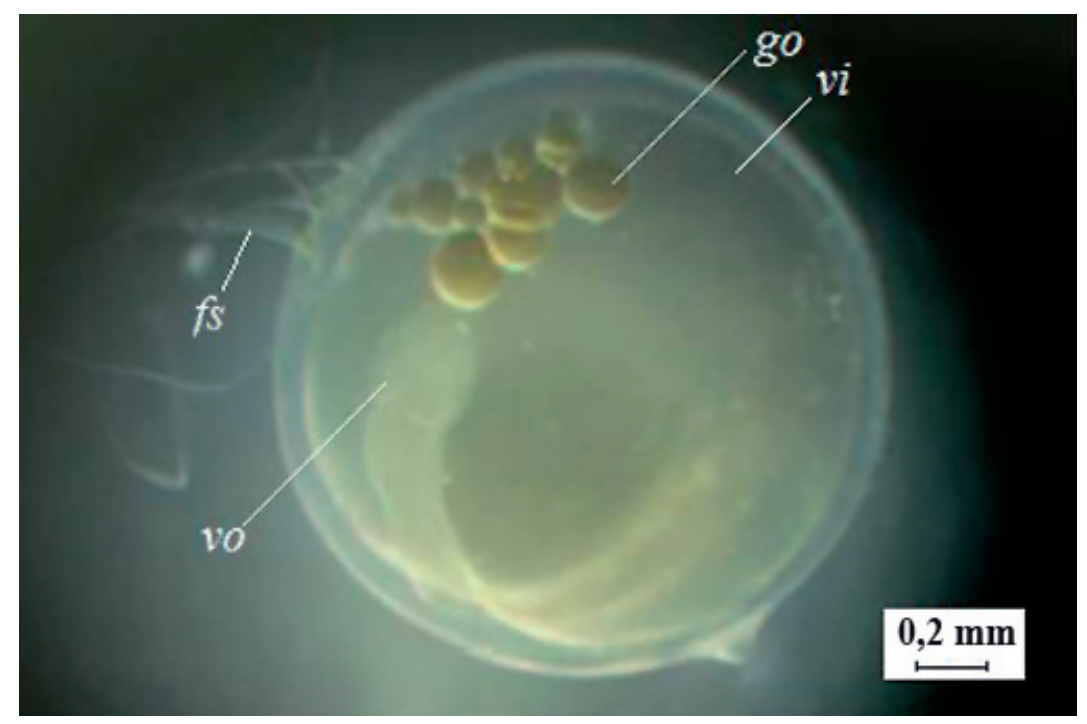

FIgURA 5. Embrión de Basilichthys australis en estado de embrión inicial avanzado. Se aprecian gotas oleosas (go), filamentos de sujeción $(f s)$, vitelo (vi) con región caudal adosada y vesículas ópticas (vo) incipientes.

FIGURE 5. Basilichthys australis embryo with advanced initial embryo stage. Oil drops (go) inside the egg, attachment filaments ( $f s$ ), caudal portion attached to yolk $(v i)$ and emerging optic vesicles $(v o)$.

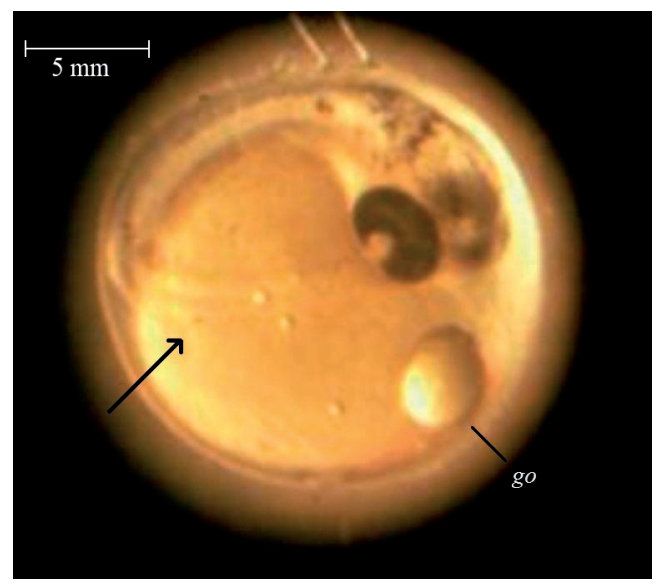

Figura 6. Embrión de Basilichthys australis en estado de embrión final intermedio con la porción caudal libre (flecha) y una única gota oleosa $(g o)$.

FIGURE 6. Basilichthys australis embryo in intermediate final embryo stage with tail release (arrow) and only one oil globule (go). 
Los huevos tienen forma esférica (Fig. 7) con coloración variable, desde amarillo a naranjo suave y un diámetro promedio de $1 \mathrm{~mm}$. La envoltura protectora (Fig. 7a) es transparente y rugosa, presentando gran cantidad de poros, posiblemente destinados a facilitar el intercambio gaseoso entre el huevo y su medio. El vitelo es uniforme, esférico y ligeramente coloreado de tono amarillo, ocupando una gran fracción del volumen del huevo (Fig. 7b). A diferencia de los huevos de B. australis en estado de embrión inicial, éstos poseen generalmente una sola gota oleosa de gran tamaño en todas las fases (Fig. 7b, c, d). La incubación de huevos provenientes de la zona de desagüe del lago Riñihue permitió describir cualitativamente los siguientes estadíos embrionales. Embrión inicial: La fase de blástula se observa como una lámina perivitelina donde es dificultoso reconocer los límites celulares. Esta ocupa una superficie amplia pero no muy alargada sobre el vitelo (Fig. 7b). Caudal libre: En este estado las tres vesículas encefálicas ya se observan claramente (Fig. 7c). Dos laterales corresponden a las vesículas ópticas, y la central al cerebro anterior. La aleta caudal se encuentra separada del vitelo (Fig. 7c). Otros rasgos morfológicos ya son identificables e.g. somitos y miómeros caudales. Embrión final: El tamaño del embrión aumenta considerablemente. Es posible distinguir con claridad la pigmentación de los ojos, y la irrigación sanguínea del organismo y del vitelo (Fig. 7d), además de la formación del corazón bicamerado. Parte de la aleta caudal se enrolla sobre el vitelo. El embrión ocupa casi la totalidad del espacio al interior del huevo y se enrolla sobre si mismo sólo una vez (Fig. 7d).
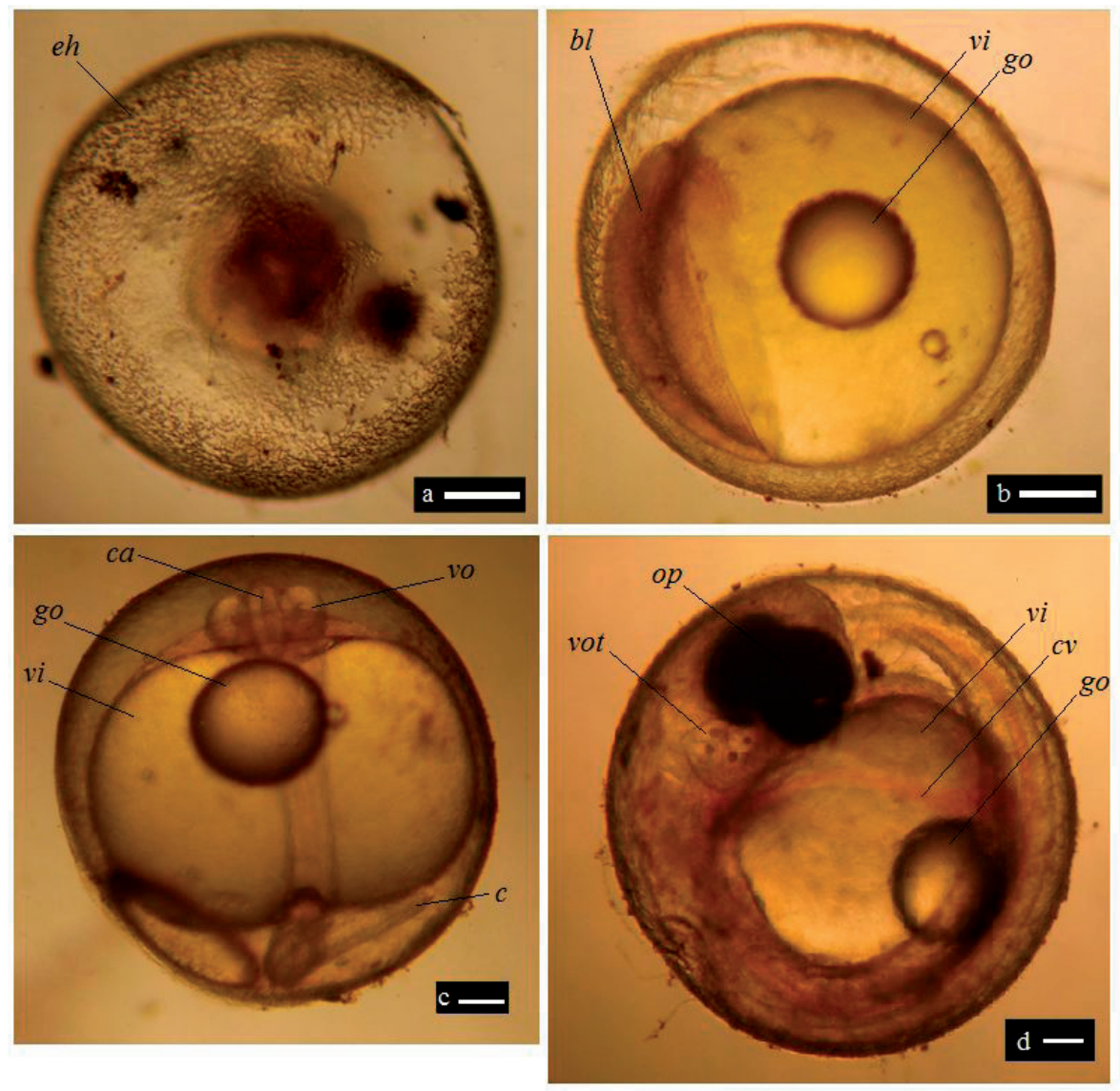

Figura 7. Huevo y embriones de Percilia gillissi. a) Detalle de la envoltura del huevo (eh); b) Huevo en estado de embrión inicial; c) Huevo en estado caudal libre; y d) Huevo en estado de embrión final donde se puede apreciar la circulación vitelina $(c v)$. Barras= 0,2 mm. Abreviaciones: blástula $(b l)$, caudal no adosada al vitelo $(c)$, cerebro anterior $(c a)$, gota oleosa (go), ojos pigmentados (op), vitelo (vi), vesícula óptica (vo) y vesícula ótica (vot).

Figure 7. Egg and embryos of Percilia gilliss. a) Coverage detail; b) Egg in initial embryo stage; c) Egg in free caudal stage; and d) Egg in final embryo stage where is possible appreciate the vitelline circulation $(c v)$. Bars $=0.2 \mathrm{~mm}$. Abbreviations: blastule $(b l)$, tail not attach to yolk $(c)$, forebrain $(c a)$, oil globule $(g o)$, pigmented eyes $(o p)$, and yolk (vi), optic vesicle (vo), and otic vesicle (vot). 
En el río, las larvas se encontraron en ambientes de pozas de hasta $30 \mathrm{~cm}$ de profundidad con sustrato fangoso y abundante materia orgánica en descomposición, especialmente hojas de árboles ribereños. Las larvas comienzan a aparecer en el río desde diciembre y se las encuentra hasta fines de marzo (Fig. 1). Las fases del desarrollo larval observadas son los siguientes. Estadío larval vitelino: Después de la eclosión, la larva en general es incolora y mantiene gran parte del vitelo, el cual no se extiende más allá de la porción cefálica. Los ojos se encuentran bien desarrollados, presentando pigmentación. La boca no se ha desarrollado. Algunas larvas no presentaron pigmentación al momento de la eclosión (Fig. 8a), en cambio otras sí presentaron pigmentación
(Fig. 8b); poseían melanóforos en la zona dorsal cefálica (Fig. 8b). Pre-flexión: En esta etapa aún no aparecen los elementos de soporte de la aleta caudal. Es característico también que la larva se mantenga ligeramente encorvada (Fig. 8c). En este estado la larva ha absorbido la totalidad de las reservas del vitelo, pero manteniendo la gota oleosa. (Fig. 9). El desarrollo de la mandíbula es evidente, lo cual la habilita para la alimentación exógena. En este estado, con la reducción del saco vitelino, la larva adopta la forma hidrodinámica final, donde resalta la aleta caudal de forma redondeada, con leve pigmentación en la zona caudal ventral (Fig. 8c).
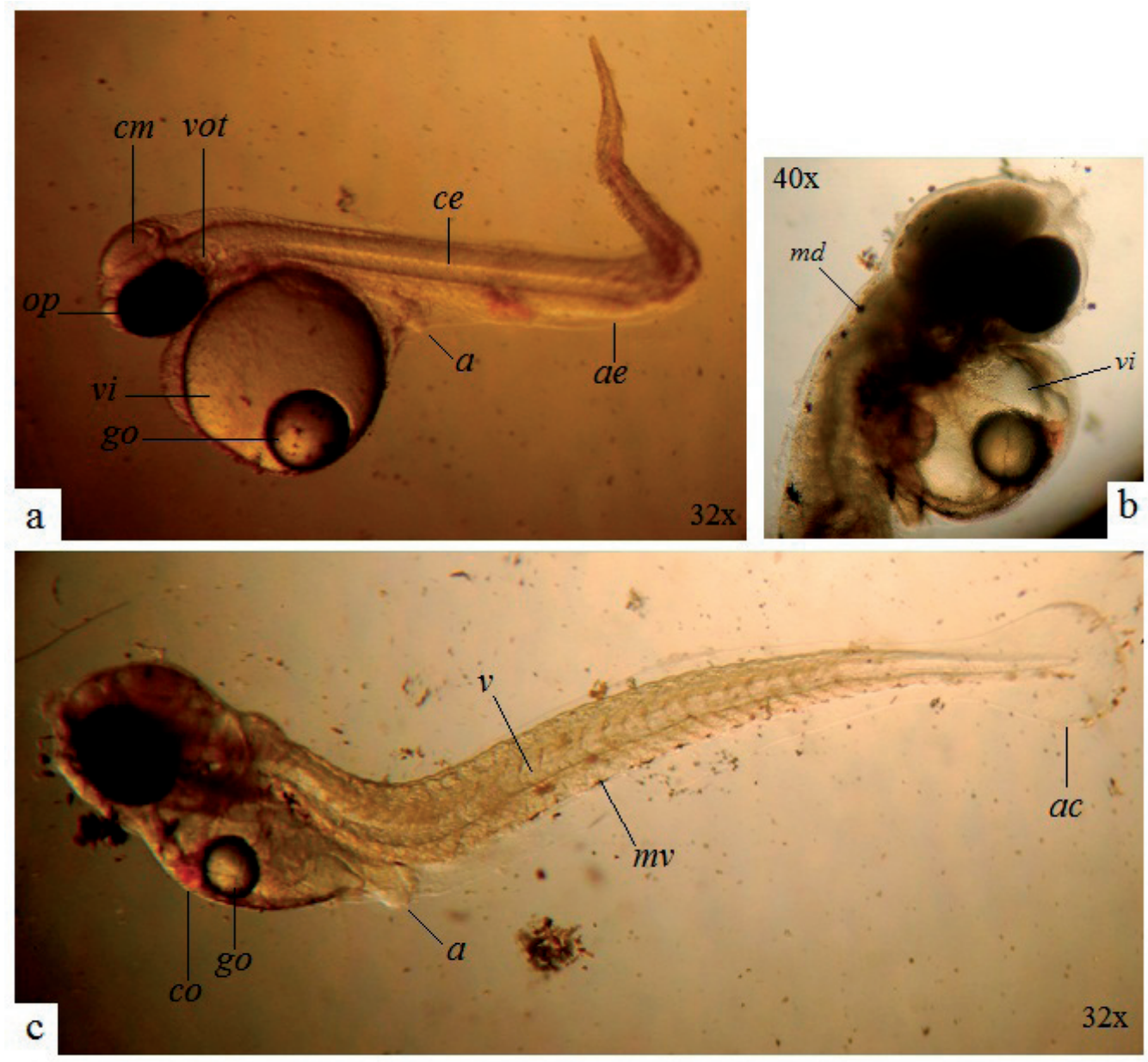

Figura 8. Larvas eclosionadas de Percilia gillissi. Es posible observar el proceso de consumo del saco vitelino (vi) con la mantención de la gota oleosa $(\mathrm{go})$. a) Larva en estado larval vitelino (Aumento 32x); b) Detalle de la región cefálica con melanóforos dorsales $(m d)$ en estado larval vitelino avanzado (Aumento 40x); y c) Larva en estado de preflexión (Aumento 32x). Abreviaciones: abertura anal ( $a$ ), aleta caudal ( $a c)$, aleta embrionaria (ae), cordón espinal (ce), cerebro medio $(\mathrm{cm})$, corazón $(\mathrm{co})$, melanóforos ventrales $(\mathrm{mv})$, ojos $(\mathrm{op})$, vertebras (v) y vesícula ótica (vot).

Figure 8. Hatched larvae of Percilia gillissi. It is possible view the process of consumption of yolk-sac (vi) with maintenance of oil globule (go). a) Larvae in Yolk larval stage (Augment 32x); b) Detail of cephalic region of larvae with dorsal melanophores $(m d)$ in advanced Yolk larval stage (Augment 40x); and c) Larvae in Preflexion stage (Augment 32x). Abbreviation: anal pore (a), caudal fin (ac), embryonic fin $(a e)$, spinal cord $(\mathrm{ce})$, midbrain $(\mathrm{cm})$, heart $(\mathrm{co})$, ventral melanophores $(\mathrm{mv})$, eyes $(\mathrm{op})$, vertebrae $(\mathrm{v})$, and otic vesicle (vot). 
Geotria australis. Debido a las descripciones previas (Neira 1984; Ruiz 1993), los esfuerzos de búsqueda de huevos fueron dirigidos a ambientes ritrales en períodos de bajo caudal, sin obtener resultados positivos. A pesar del escaso conocimiento sobre los sitios y momentos de postura de estas lampreas (Jellyman \& Glova 2002; James 2008) se ha especulado que el desove corresponde a una fase de muy corta duración, y principalmente asociada a pequeños tributarios, como lo han descrito Jellyman et al. (2002) en Nueva Zelanda. En otras especies de la familia, los sitios de desove están asociados a ríos con grava y corriente donde construyen cavidades ovales poco profundas para depositar los huevos (McDowall 1990), lo cual ha sido descrito en detalle por Maitland (2003) para ríos del Reino Unido. Adicionalmente, se postula que los huevos podrían ser adhesivos (James 2008).

En el río San Pedro se encontraron los estados larvales de ammocetes y macroftalmia, principalmente asociados a ambientes con sustrato fino a fangoso. Ambas son muy alargadas y con coloración oscura sobre el dorso, pero pueden diferenciarse entre sí por el desarrollo del ojo, el cual es conspicuo en macroftalmia. Tal como lo han descrito Neira (1984) y Jellyman \& Glova (2002), en el río San Pedro se encontró que las larvas ammocetes son arrastradas por la corriente hacia ambientes someros, donde cohabitan enterradas con macroftalmias en pozas con predominancia de sustrato fino (fango o arena). Al contrario de esta segregación espacial, los estados larvales de G. australis no muestran una dinámica temporal, sin diferencias de abundancia entre meses (Valdovinos et al. 2012). De hecho, su presencia ocurre durante todo el año (Fig. 1), lo que se asocia al largo período de desarrollo larval de la especie.

Laslarvas sonfiltradoras dealgas, detritus ymicroorganismos, y posteriormente migran a ambientes marinos cambiando de rol trófico a parásitos de teleósteos (Empson \& Meredith 1987; Jellyman et al. 2002). Se estima que los adultos permanecen alrededor de 2-4 años en el mar (James 2008). En cambio la fase larval tendría una duración que se extiende de 3,25 a 4,25 años (Potter \& Hilliard 1986), pero no se han reportado seguimientos detallados a nivel nacional.

Trichomycterus areolatus. Aún cuando no se encontraron huevos de T. areolatus, postulamos que el desove ocurre entre octubre a diciembre, dado el hallazgo de hembras con ovocitos maduros entre septiembre y diciembre. Esto coincide con lo informado por Manríquez et al. (1988) y Ruiz et al. (1993) para otros sistemas fluviales del centro sur de Chile. Los ovocitos maduros tienen aspecto amarillo brillante y su diámetro oscila entre 1,51 a 2,1 mm (Manríquez et al. 1988).

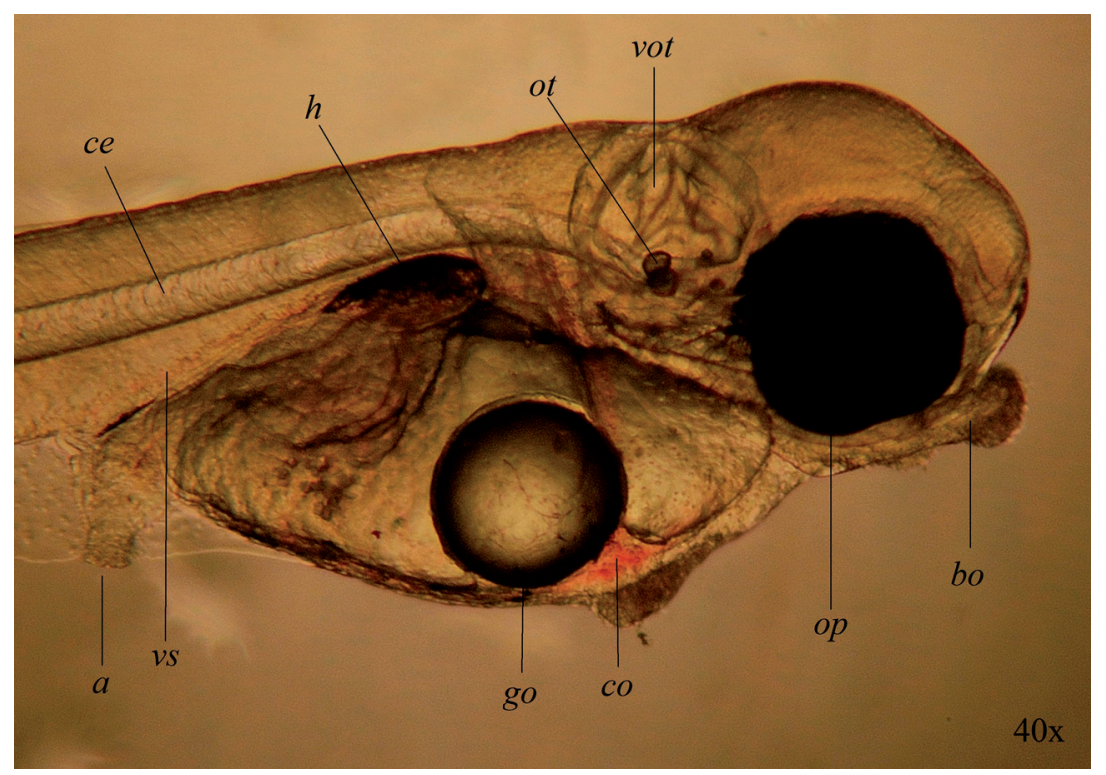

Figura 9. Detalle de la región céfalo-torácica de una larva de Percilia gillissi en un estado avanzado de preflexión. Se observa el notable desarrollo de la mandíbula inferior y con ello la boca (bo) y el comienzo de la alimentación exógena. Aumento 40x. Abreviaciones: ano ( $a$ ), cuerda espinal (ce), corazón ( $c o$ ), gota oleosa $(g o)$, hígado $(h)$, ojos $(o p)$, otolitos $(o t)$, vesícula ótica (vot) y vasos sanguíneos (vs).

FIgURE 9. Detail of cephalo-thoracic region of Percilia gillissi larvae in advanced preflexion stage. It clearly show the development of the lower jaw and hence the mouth (bo), with it beginning of exogenous feeding. Magnification 40x. Abbreviations: anus (a), spinal cord (ce), heart $(c o)$, oil globule $(g o)$, liver $(h)$, eyes $(o p)$, otoliths (ot), otic vesicle (vot), and blood vessels ( $v s)$. 
Las larvas de $T$. areolatus presentan aleta primordial, evidenciando su reciente eclosión, con tenue pigmentación característica de la especie. Fueron encontradas asociadas a ambientes de pozas someras con sustrato de arcilla o fangoso, en algunas oportunidades junto con larvas de B. australis. Siempre se encontraron segregadas de los adultos, corroborando la inexistencia de cuidado parental (Manríquez et al. 1988). La mayor abundancia de larvas se encuentra a fines de diciembre (Fig. 1), distribuyéndose a lo largo de todo el río San Pedro en esa época. En este mismo ambiente fueron encontrados individuos postlarvales (juveniles) de esta especie (Fig. 10), pero tales hallazgos fueron escasos. Sus tallas fluctuaron entre $15-17 \mathrm{~mm}$ y presentaron pigmentación similar al adulto, aunque de tonalidad más pálida. Destaca el gran tamaño de su cabeza y ojos. Barbillas bien desarrolladas. Cuerpo bastante alargado y más bien cilíndrico que aplastado dorso-ventralmente.

Diplomystes camposensis. La búsqueda de huevos de esta especie ("tollo de agua dulce") estuvo dirigida a ambientes someros con sustratos de gravas, piedras y bolones, sin obtener resultados positivos. Tampoco se encontraron larvas de esta especie.
Aún cuando existe poca información general para las especies de este género, se espera que dada la estrecha semejanza filogenética entre ellas, sus ciclos reproductivos y estados ontogenéticos sean muy similares (Arratia 1987). Así por ejemplo, se ha descrito para la especie congenérica D. nahuelbutaensis, presente entre las cuencas del río Itata al Imperial, la presencia de un saco ovárico con pocos ovocitos de gran tamaño (hasta $3 \mathrm{~mm}$ en estado maduro) y con gran cantidad de vitelo (Vila et al. 1996). Los huevos son de tipo demersal (Vila et al. 1996) y la época de desove es concordante con los caudales más bajos y temperaturas altas del río, entre verano y otoño (Vila et al. 1996; Lundberg et al. 2004).

Según Lunberg et al. (2004) los especímenes de Diplomystes y de la mayoría de las especies de siluriformes entre 7-16 mm aún presentan remanentes de saco vitelino. Asimismo, el gran tamaño descrito para los huevos y la baja fecundidad de D. nahuelbutaensis (Vila et al. 1996) serían concordantes con la propuesta de cuidado parental postulada por Habit (2005), y en general, para siluriformes (Nakatani et al. 2001). Ello podría explicar por qué no se encontraron larvas, las que no estarían asociadas a ambientes ribereños, al igual que los huevos.

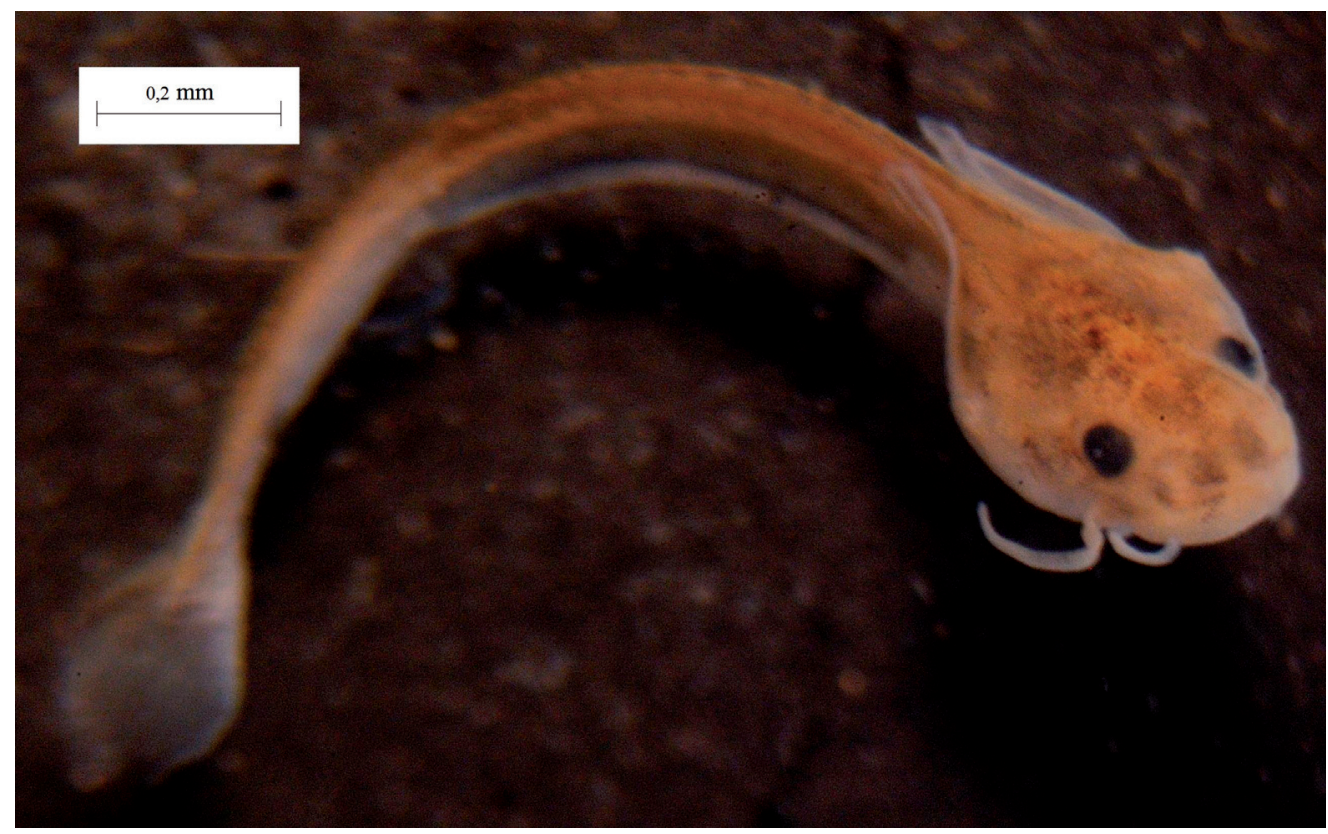

Figura 10. Postlarva o primer estado de juvenil de Trichomycterus aerolatus. Se destaca el gran tamaño de su cabeza en comparación al cuerpo muy delgado y el desarrollo de las barbillas.

Figure 10. Postlarvae of juvenile of Trichomycterus aerolatus. See the big cephalic region compare with the thin and long body and the chins fully development. 
Los individuos más pequeños que se capturaron de $D$. camposensis midieron $15 \mathrm{~mm}$ de longitud estándar. Estos carecen de saco vitelino y de la aleta caudal continua característica de la larva en preflexión. Al igual que en otros siluriformes, poseen cabeza y ojos grandes, y un patrón de pigmentación muy similar al del adulto (Fig. 11). En concordancia con Lundberg et al. (2004) para D. nahuelbutaensis de 1,3 a $1,4 \mathrm{~mm}$ en el río Biobío, los primeros juveniles de $D$. camposensis se encontraron en ambientes de rápidos someros, entre enero y abril de cada año (Fig. 1). Aún cuando la captura de estas tallas de individuos no es frecuente, se les encuentra formando agrupaciones de aproximadamente 15 individuos, asociados a ambientes de rápidos de profundidad variables $(10 \mathrm{a} 100 \mathrm{~cm}) \mathrm{con}$ predominancia de sustrato de bolones ( $>15 \mathrm{~cm}$ diámetro). Este comportamiento gregario es distinto al observado en individuos de mayor talla, los que se encuentran solitarios.

Percichthys trucha. No se encontraron huevos de P. trucha ("percas"). Ruiz \& Marchant (2004) informan huevos de 1 $\mathrm{mm}$ de diámetro en ovarios de hembras en proceso de desove durante la época de primavera, entre octubre a noviembre. Golusda (1927) y Ruiz (1993) reportan fechas similares para el desove de hembras, sin embargo aún se desconocen los sitios de ovipostura y si éstos están restringidos a ríos o lagos. Para el lago Moreno (Argentina) se ha informado de la presencia de masas de huevos encontradas entre las plantas acuáticas de la zona litoral a una profundidad de 1-3 m (Buria et al. 2007). En sistemas fluviales argentinos, ya en septiembre las hembras de $P$. trucha y $P$. colhuapiensis (MacDonagh 1955) se encuentran en etapa postdesove (Amalfi 2009). Sobre los $370 \mathrm{~mm}$ de talla, esta última especie puede presentar ovarios hasta con 250.000 ovocitos (Amalfi 2009). Desova una vez al año y lo realiza en lapsos cortos $\mathrm{y}$ en forma total, es decir que las ovas maduran todas de una sola vez (Amalfi 2009). Nakatani et al. (2001) describe otros perciformes e.g. Sciaenidae y Cichlidae, que utilizan sistemas principalmente lénticos para desovar, presentando además huevos de tipo demersal y/o adheridos a distintos sustratos como rocas o algas submarinas.

A pesar de la intensa búsqueda en ambientes ribereños, no se encontraron larvas de percas. Los hábitats usados por las larvas no estarían limitados a un único ambiente, por lo que no es descartable que esta especie utilice tanto sistemas lóticos como lénticos para su reproducción.

En el río San Pedro, los juveniles de $P$. trucha se encontraron en ambientes de pozas $(0 \mathrm{~m} / \mathrm{s})$ someras $(\sim 50 \mathrm{~cm})$ entre marzo y mediados de abril (Fig. 1). En esa fecha también fueron colectados abundantes juveniles en el litoral del lago Riñihue. Estos individuos se caracterizan por un gran tamaño de la porción cefálica del cuerpo y una coloración plateada brillante.

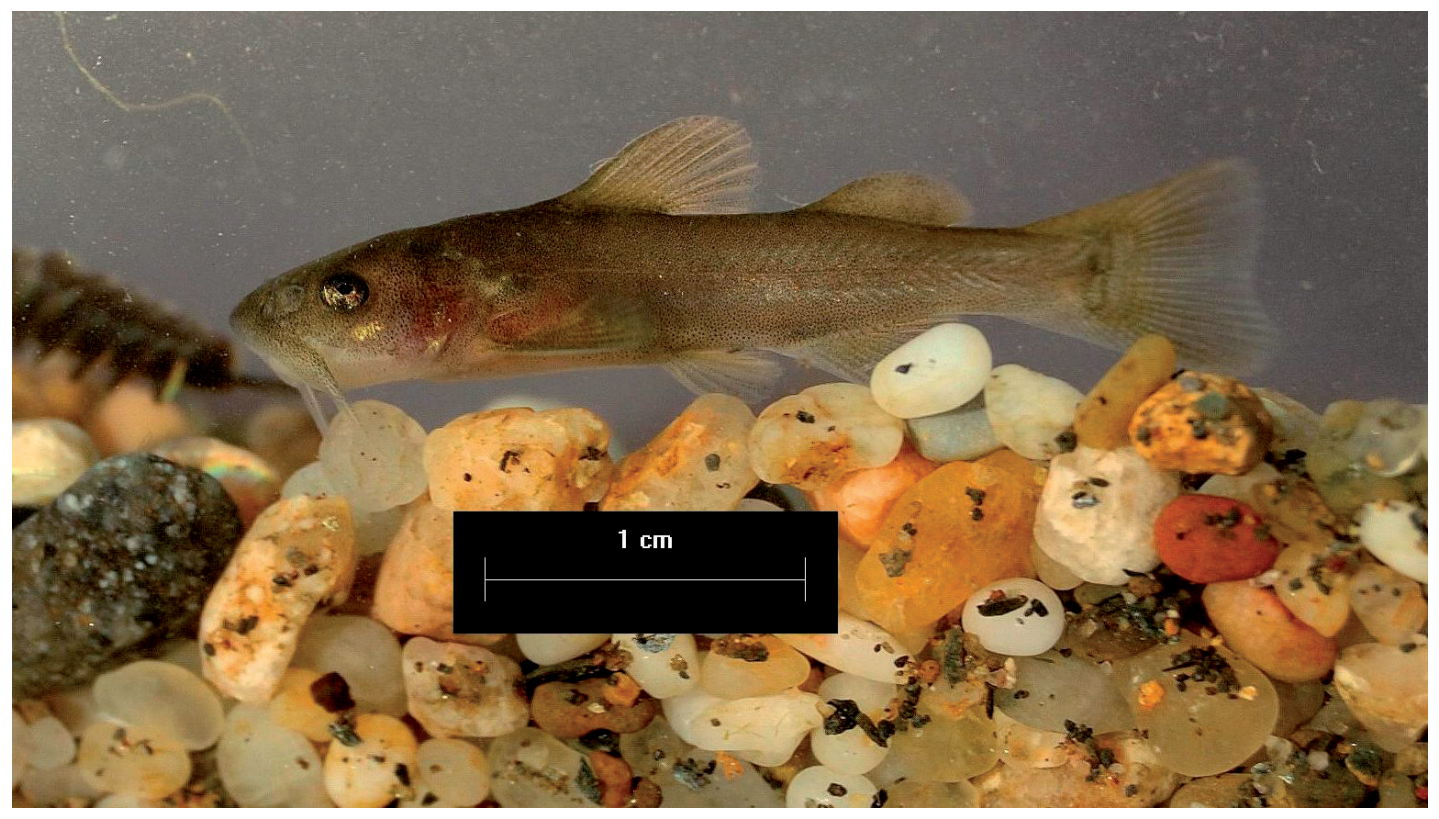

Figura 11. Juvenil avanzado de Diplomystes camposensis. Se aprecia que ya en este estado temprano posee una gran semejanza a la fase adulta.

FIGURE 11. Advanced juvenile of Diplomystes camposensis. This early stage is very similar to adult phase. 
Cheirodon australe. Durante el período de estudio no fueron encontrados huevos. Tampoco existe información sobre sitios de postura, ni de características morfológicas de los huevos para esta especie, comúnmente llamada "pochas". Se encontraron escasas fases de postlarvas asociadas a ambientes de pozas someras durante febrero y marzo. Los juveniles de año son abundantes hacia finales de marzo, incrementando su abundancia principalmente en mayo (Fig. 1). Durante junio se les encuentra asociados a las planicies de inundación.

\section{CONCLUSIONES}

El presente estudio permitió encontrar y describir al menos uno de los primeros estadíos del ciclo de vida -huevos, larvas o juveniles de ocho especies nativas. Los ciclos de vida de dos de éstas especies eran conocidas previamente por su interés comercial (G. maculatus y B. australis). No obstante, este trabajo comenta y describe por primera vez los estadíos de desarrollo embrionario y larval de $P$. gillissi.

En general, las épocas de ocurrencia de estos estadíos muestran una alta relación con la dinámica de los caudales, demostrando la dependencia de las épocas de reproducción y desove con el régimen de caudal (ver Cifuentes et al. 2012). En este sentido, el régimen de caudal del río no sólo gatilla los eventos de reproducción, sino que crea los hábitats adecuados para la postura y crianza de estos estadíos altamente lábiles.

El escaso conocimiento de sitios de postura y en general de las características morfológicas dificulta el hallazgo de los primeros estadíos. No obstante, dado que éste estudio se efectuó preferentemente en ambientes ribereños, se vuelve indispensable complementar la búsqueda de primeros estadíos, no detectados, en ambientes más profundos o correntosos. Asimismo, la información presentada en este trabajo permitirá facilitar la búsqueda de dichos estadíos y continuar su estudio más acabado. Finalmente, la obtención de más información sobre estos estadíos requiere de muestreos sistemáticos de largo plazo, que incluyan la búsqueda específica de ellos.

\section{AGRADECIMIENTOS}

Agradecemos a COLBUN S.A. por financiar este estudio y al proyecto DIUC Semilla Patagonia 210.310.057-1SP por el financiamiento de la publicación.. A los propietarios de los predios aledaños al río por permitirnos ingresar a ellos, y muy especialmente al Hotel Riñimapu por las facilidades brindadas para llevar a cabo esta investigación. Igualmente se agradece a todas las personas que directa o indirectamente participaron en la elaboración de este estudio. Finalmente se agradece al proyecto Fondecyt 1110441 que permitió la finalización de este manuscrito.

\section{BIBLIOGRAFÍA}

Ahlstrom, E.H. \& Moser, H.G. 1976. Eggs and larvae of fishes and their role in systematic investigations and in fisheries. Revue des Travaux de 1'Institut des Peches Maritimes 40(3-4): 379-398.

Amalfi, M. N. 2009. Consideraciones sobre las percas (Percichthys colhuapiensis y P.trucha) de la Patagonia norte - Años 1955 a 1957. Comparaciones con material de años recientes. ProBiota, FCNyM, UNLP, La Plata, Argentina, Vol.X 180pp.

ArRatia, G. 1987. Description of the primitive family Diplomystidae (Siluriformes, Teleostei, Pisces): morphology, taxonomy, and phylogenetic implications. Bonner Zoologische Monographien 24:1-120.

Bagenal, T.B. \& Nellen, W. 1980. Sampling eggs, larvae and juvenile fish. Guidelines for sampling fish in Inland Waters. Backiel, T. \& Welcomme, R.L. Eds. EIFAC Technical Paper. Rome, Italy. 3-36 pp.

Barriga, J., Battini, M., Macchi, P., Milano, D. \& Cussac, V. 2002. Spatial and temporal distribution of landlocked Galaxias maculates and Galaxias platei (Pisces: Galaxiidae) in a lake in the South American Andes. New Zealand Journal of Marine and Freshwater Research 36:345-359.

Barriga, J. P., Battini, M. A. \& Cussac, V. E. 2007. Annual dynamics variation of a landlocked Galaxias maculatus (Jenyns 1842) population in a Northern Patagonian river: occurrence of juvenile upstream migration. Journal of Applied Ichthyology 23:128-135.

BAttini, M.A. 1998. Los estadios tempranos de vida de Galaxias maculatus (Jenyns,1842) y Odontesthes hatcheri (Eigenmann, 1909), con especial referencia a su alimentación y crecimiento, Tesis Doctoral, Universidad Nacional del Comahue, Bariloche, Argentina. 100 pp.

Benzie, V. 1968a. Stages in the normal development of Galaxias maculatus attenuatus (Jenyns). New Zealand Journal of Marine and Freshwater Research 2:606-627.

BenZIE, V. 1968b. Some ecological aspects of the spawning behaviour and early development of the common whitebait, Galaxias maculatus attenuatus (Jenyns). Proceedings of the New Zealand Ecology Society 15:31-39.

Boy, C.C., Pérez, A.F., Lattuca, M.E., Calvo, J.E. \& Morriconi, R. 2009. Reproductive biology of Galaxias maculatus (Jenyns 1842) in Río Ovando estuary, a high-latitude environment in southernmost Patagonia. Journal of Applied Ichthyology 25:661-668.

Buria, L., Walde, S. J., Battini, M., Macchi, P. J., Alonso, M., Ruzzante, D. E. \& Cussac, V. E. 2007. Movement of a South American perch Percichthys trucha in a mountain Patagonian lake during spawning and prespawning periods. Journal of Fish Biology 70:215-230.

CAmpos, H. 1970. Galaxias maculatus (Jenyns) en Chile, con especial referencia a su reproducción. Boletín del Museo Nacional de Historia Natural de Chile 31:5-20. 
Cervellini, P.M., Battini, M.A. \& Cussac, V.E. 1993. Ontogenetic shifts in the diet of Galaxias maculatus (Galaxiidae) and Odontesthes microlepidotus (Atherinidae). Environmental Biology of Fishes 36:283-290.

Chapman, A., Morgan, D.L., Beatty, S.J. \& Gill, H.S. 2006. Variation in life history of land-locked lacustrine and riverine populations of Galaxias maculatus (Jenyns 1842) in Western Australia. Environmental Biology of Fishes 77:21-37.

Cifuentes, R., J., González, G., Montoya, A., Jara, N., Ortíz., P. Piedra \& E., Habit. 2012. Relación longitud-peso y factor de condición de los peces nativos del rio san pedro (cuenca del río valdivia, Chile). Gayana 76 (Número Especial): 101-110.

Colin, N., Piedra, P., \& Habit , E. 2012. Variaciones espaciales y temporales de las comunidades ribereñas de peces en un sistema fluvial no intervenido: río San Pedro, Cuenca del Valdivia (Chile). Gayana 76 (Número Especial): 24-35.

Cussac, V., Ortubay, S., Iglesias, G., Milano, D., Lattuca, E., Barriga, P. Battini, M. \& Gross, M. 2004. The distribution of South American galaxiid fishes: the role of biological traits and post-Glacial history. Journal of Biogeography 31:103-121.

Duarte, W., Feito, R., Jara, C., Moreno, C. \& Orellana, E. 1971. Ictiofauna del sistema hidrográfico del río Maipo. Boletín del Museo Nacional Historia Natural de Chile 32:227268.

Empson, P. \& Meredith, A. 1987. Downstream migration of Geotria australis juveniles in the lower Waikato River (Note). New Zealand Journal of Marine \& Freshwater Research 21(4):643-644.

García De Jalón D., Mayo, M., Hervella, F., Barceló, E. \& Fernández, T. 1993. Principios y técnicas de gestión de la pesca en aguas continentales. Mundi Prensa, Madrid, España. 247 pp.

García, A., González, J. \& Habit, E. 2012. Caracterización de Habitats de peces nativos en el río San Pedro (Cuenca del rio Valdivia, Chile). Gayana 76 (Número Especial): 36-44.

Golusda, P. 1927. Aclimatación y cultivo de especies salmonídeas en Chile. Boletín de la Sociedad de Biología de Concepción 1(1-2):80-100.

Habit, E. 2005. Aspectos de la biología y hábitat de un pez endémico de Chile en peligro de extinción (Diplomystes nahuelbutaensis Arratia, 1987). Interciencia 30:8-11.

Habit, E., Dyer, B. \& Vila, I. 2006. Estado de conocimiento de los peces dulceacuícolas de Chile: estado de su conocimiento. Gayana 70(1):100-112.

Hempel, G. 1973. On the use of ichthyoplankton surveys. FAO Fisheries Technical Paper. Rome, 122:1-2.

Huaquín, N. \& Araya, L. 1986. Caracterización de los estados del desarrollo embrionario del pejerrey Basilichthys autralis (Eigenmann, 1927). Biología Pesquera 15:27-44.

James, A. 2008. Ecology of the New Zealand Lamprey (Geotria australis) - Aliterature review. Department of Conservation, Wanganui Conservancy. Private Bag 3016. Wanganui, New Zealand. 28 pp.

Jellyman, D. \& Glova G. 2002. Habitat use by juvenile lampreys (Geotria australis) in a large New Zealand river. New Zealand Journal of Marine and Freshwater Research 36:503-510.
Jellyman, D., Glova, G. \& Sykes, J. 2002. Movements and habitats of adult lamprey (Geotria australis) in two New Zealand waterways. New Zealand Journal of Marine and Freshwater Research 36:53-65.

Kilian, E. \& Campos, H. 1969. Susswasserschwamme als ortder Brutpflege eipe Fisches. Naturwissenschaften 56(5):333334.

LASKer, R. 1987. Use of fish eggs and larvae in Probing Some Major Problems in Fisheries and Aquaculture. American Fisheries Society Symposium 2:1-16.

Lundberg, J., Berra, T., Tim, M., Friel, J. \& John, P. 2004. First description of small juveniles of the primitive catfish Diplomystes (Siluriformes: Diplomystidae). Ichthyological Exploration of Freshwaters 15(1):71-82.

Maitland, P. 2003. Ecology of the River, Brook and Sea Lamprey. Conserving Natura 2000 Rivers Ecology Series. English Nature, Peterborough. Vol. V.

Manríquez, A., Huaquín, L., Arellano, M. \& Arratia, G. 1988. Aspectos reproductivos de Trichomycterus areolatus Valenciennes, 1846 (Pisces: Teleostei: Siluriformes) en río Angostura, Chile. Studies on Neotropical Fauna and Environment 23:89-102.

McDowall, R. M. 1976. The role of estuaries in the life cycles of fishes in New Zealand. Proceedings of the New Zealand Ecological Society 23:27-32.

Mcdowall, R. 1990. New Zealand freshwater fishes: a natural history and guide. Heinemann Reed, Auckland, New Zealand. $553 \mathrm{pp}$.

Moreno, C., Urzúa, R. \& Bahamonde, N. 1977. Breading season, sexual rate and fecundity of Basilichthys australis Eigenmann 1927, from Maipo River, Chile. (Atherinidae, Pisces). Studies on Neotropical Fauna and Environment 12(3):217-223.

Nakatani, K., Agostinho A., Baumgartner, G., Bialetzki, A., Vanderlei, P., Cavicchioli, M. \& Pavanelli, C. 2001. Ovos e larvas de peixes de agua doce: desenvolvimento e manual de identificacao. Conselho Editorial, Brasil. 378 pp.

NeIRA, F. 1984. Biomorfología de las lampreas parásitas chilenas Geotria australis Gray, 1851 y Mordacia lapicida (Gray, 1851) (Petromyzontiforms). Gayana 48:3-40.

Nellen, W. \& Schnack, D. 1975. Sampling problems and methods of fish eggs and larvae Investigations with special reference to inland waters. Symposium on the Methodology for the Survey, Monitoring and Appraisal of Fishery Resources in Lakes and Large Rivers. Welcomme, R.L. Ed., EIFAC Technical Paper.Vol. II 538-551 pp.

Peredo, S. \& Sobarzo, C. 1993. Microestructura del ovario y ovogénesis en Galaxias maculatus (Jenyns, 1842) (Teleostei: Galaxiidae). Biología Pesquera 22: 23-32.

Peredo, S. \& Sobarzo, C. 1994. Actividad gonádica estacional de Galaxias maculatus en el río Cautín. IX región, Chile. Boletín de la Sociedad de Biología de Concepción 65:6570.

Pollard, D.A. 1971. The biology of a landlocked form of the normally catadromous salmoniform fish Galaxias maculatus (Jenyns). I. Life cycle and origin. Australian Journal of Marine and Freshwater Research 22:91-123.

Potter, I. \& Hilliard, R. 1986. Growth and the average duration of larval life in the southern hemisphere lamprey, Geotria australis, Gray. Experientia 42:1170-1173. 
RuIz, V. 1993. Ictiofauna del río Andalién (Concepción, Chile). Gayana 57:109-278.

Ruiz, V.H., López, M.T., Moyano, H.I. \& Marchant, M. 1993. Ictiología del Alto Biobío: aspectos taxonómicos, alimentarios, reproductivos y ecológicos con una discusión sobre la hoya. Gayana 57:77-88.

Ruiz, H. \& Marchant, M. 2004. Ictiofauna de aguas continentales de Chile. Facultad de Ciencias Naturales y Oceanográficas, Universidad de Concepción. 356 pp.

Valdovinos, C., E. Habit, A. Jara, P. Piedra, J. González \& J. SAlvo. 2012. Dinámica espacio-temporal de 13 especies de peces nativos en un ecotono lacustre-fluvial de la cuenca del río Valdivia (Chile). Gayana 76 (Número Especial): 45-58.

Victoriano, P., Vera, I., Olmos, V., Dib, M., Insunza, B., Muñoz-
Ramírez, C., Montoya, R., Jara, A. \& Habit, E. 2011. Patrones Idiosincráticos de Diversidad Genética de Peces Nativos del río San Pedro, un Sistema de la Región Glaciada del Sur de Chile. Gayana 76 (Número Especial): 71-85.

Vila, I., Soto, D., \& Bahamondes, I. 1981. Age and growth of Basilichthys australis Eigenmann 1927 in Rapel Reservoir, Chile. (Pisces, Atherinidae). Studies on Neotropical Fauna and Environment 16(1):9-22.

Vila, I., Contreras, M. \& Fuentes, L. 1996. Reproducción de Diplomystes nahuelbutensis Arratia, 1987 (Pises: Diplomystidae). Gayana Oceanología 4:129-137.

Vila, I. \& Pardo, R. 2008. Peces límnicos. En: Biodiversidad de Chile, Patrimonio y desafíos, (Eds. Conama, Ocho Libros. Santiago de Chile, 640 pp.

Recibido: 02.01.12

Aceptado: 27.02.12 